\title{
A pesquisa em educação matemática: a prevalência da abordagem qualitativa ${ }^{1}$
}

Maria Aparecida Viggiani Bicudo

\begin{abstract}
Resumo
O foco do tratado neste artigo é a pesquisa qualitativa, qualquer que seja a modalidade assumida, como sendo a dominante na produção do conhecimento em educação matemática. Busca-se dar conta do "por que" isso ocorre, em termos epistemológicos e aos concernentes à realidade do objeto investigado, que dizem respeito à concepção de educação e de ser humano em formação. Juntamente com essas questões, é discutido o significado de qualitativo, adjetivo que qualifica a pesquisa.
\end{abstract}

Palavras-chave: Educação matemática, pesquisa qualitativa, pesquisa em educação matemática.

\begin{abstract}
Research in mathematics education: the prevalence of the qualitative approach

The focus of this article is the qualitative research, whatever the assumed modality, as the main modality of research on the mathematical education production. It is highlighted the "why" it occurs on an epistemological perspective as well as those ones concerned to the reality of the investigated object which relates to concept education and the human being in continuous education. Along with such issues it is discussed the meaning of "qualitative", adjective that qualifies the research.
\end{abstract}

Keywords: Mathematical Education, Qualitative Research, Research on Mathematical Education

${ }^{1} \mathrm{O}$ tema deste artigo foi apresentado inicialmente no EBRAPEM - Encontro Brasileiro de PósGraduação em Educação Matemática, ocorrido em Campo Grande/MS de 03 a 05 de setembro de 2011. 


\section{Introduzindo o tema}

Este texto tem por objetivo ressaltar a pesquisa em Educação Matemática, entendida como um aspecto vital de programas de Pós-Graduação, uma vez que, conforme compreendo, tal aspecto refere-se à produção do conhecimento, produto da realização de pesquisas, que os vitaliza. Portanto, tomar ciência do modo pelo qual essa produção é realizada, incluindo suas ideologias e lógicas, é preciso.

Tanto quanto a um olhar primeiro e sem maiores enfoques temáticos para as investigações efetuadas nos Programas de Pós-Graduação em Educação Matemática e suas variações como os de Educação com linha de pesquisa em Ensino de Matemática, Ensino de Ciências, e assim por diante, como quando em estudo a respeito dessa produção, em Bicudo e Paulo (2011) constata-se que sua grande maioria é conduzida mediante procedimentos da pesquisa qualitativa.

Sem colocar em questão a modalidade de pesquisa qualitativa, importa perguntar: por quê? Apressadamente, diriam alguns: porque é mais fácil, uma vez que não há necessidade de dominarem-se técnicas estatísticas e respectivos cálculos. Entretanto, para além de uma possibilidade de aparente "facilitação de procedimentos", gostaria de destacar aspectos epistemológicos e, também, aqueles concernentes à concepção de educação e de ser humano em formação. Aspectos esses que se entrelaçam, denotando uma complexidade específica à educação e, assim, evidenciam emaranhados com ensino, aprendizagem, políticas educacionais, ideologias, concepções de ciência, compreensões de história, de vida, possibilitando-nos adentrar em um campo cada vez mais abrangente e profundo e que, ambiguamente, se dá a conhecer e se esconde.

Essa complexidade se revela no objeto de estudo das investigações dessa área de pesquisa ${ }^{2}$ e, entrelaçada à exigência por se saber a respeito das características do modo de ser ou de se mostrar daquilo que está sob investigação, coloca o pesquisador diante da questão inevitável: quando quantifico, o que estou quantificando? Isso que pretendo quantificar deixa-se apreender em contagens e mensurações? O que a quantificação esclarece sobre o objeto estudado? Como quantifico? Quando qualifico, o que qualifico? Atividades de ensino? Processos

\footnotetext{
${ }^{2}$ Referimo-nos aqui à Educação Matemática como área de pesquisa para dizer de um campo de investigação que tem suas características, não fechadas e estáticas, em termos de produção de conhecimento, de perguntas que endereça, de modos de proceder na dimensão da pesquisa, bem como naquela de posicionamentos de políticas educacionais.
} 
cognitivos? Propostas públicas de educação? Como qualifico? Em que se baseia a qualificação que estou efetuando? O que ela me diz do objeto investigado? (BICUDO, 2011).

As questões destacadas no parágrafo acima abrem um leque de possíveis respostas e, mais do que isso, conduzem o investigador comprometido com sua pesquisa a efetuar um movimento de análise dos procedimentos que assume como apropriados para deslanchar o processo de produção de conhecimento que está em marcha mediante suas atividades e, ainda, refletir sobre tais procedimentos em termos epistemológicos e ontológicos.

O apresentado até aqui almeja colocar sob suspeição o que é isto que fazemos, quando pesquisamos qualitativa ou quantitativamente. Como pesquisadora, tenho trabalhado qualitativamente e, mais do que isso, tenho desenvolvido investigações e respectivos procedimentos em uma modalidade específica de pesquisa qualitativa, fenomenológica/ hermenêutica. Passarei a expor meu pensamento sobre esse modo de produzir conhecimento em Educação Matemática.

É importante, entretanto, esclarecer minha postura em relação à pesquisa qualitativa em educação: um modo de proceder que permite colocar em relevo o sujeito do processo, não olhado de modo isolado, mas contextualizado social e culturalmente; mais do que isso e principalmente, de trabalhar concebendo-o como já sendo sempre junto ao mundo e, portanto, aos outros e aos respectivos utensílios dispostos na circunvizinhança existencial, constituindo-se, ao outro e ao mundo em sua historicidade.

\section{Aspectos importantes da ação de pesquisar qualitativamente}

Foquemos, então, aspectos cruciais da pesquisa qualitativa.

Como o próprio nome já indica, trabalha-se com a qualidade. Qualidade do quê? Façamos um ensaio imaginativo com os pares: objeto/observado, fenômeno/percebido. Esse ensaio pode nos levar a dar conta de que esses pares já anunciam posturas em relação ao modo de tomar um ou outro par para investigação. Vejamos como.

O par objeto/observado indica uma postura de separação entre sujeito que efetua a observação e o objeto observado. A busca é pela qualidade, tomada como já dada e pertinente ao objeto. É como se a qualidade fosse do objeto e se mostrasse passível de ser observada. Para tanto, seriam tomadas categorizações dessa qualidade e a observação seria dirigida por essa categorização. Assim procedendo, acabaríamos por cair no caso semelhante à mensuração ou contagem de qualidades. Como exemplos, poderíamos lembrar pesquisas efetuadas no campo da Psicologia, sobre valores, aprendizagem, motivação, personalidade, inteligência etc., quando se toma o definido como aprendizagem, por exemplo, e caminha-se em direção de observar se o 
caracterizado nessa definição está presente em comportamentos do sujeito observado e, então, passa-se a interpretar os dados observados à luz da teoria em que a definição está contextualizada. Lembremos, entretanto, que não é apenas a Psicologia que procede desse modo, mas também a Linguística, Educação, Sociologia, Antropologia, disciplinas da Medicina, etc. Ou seja, disciplinas notadamente humanas e que assumem concepções positivistas, baseando-se na separação sujeito/ objeto.

O par fenômeno/percebido indica que a qualidade é percebida, mostrando-se na percepção do sujeito. Há uma doação de aspectos passíveis de serem percebidos em modos próprios de aparecer. Por exemplo, a frieza do gelo é doada enquanto frialdade, querendo com isso dizer que, em seus modos de o fenômeno mostrar-se como frio são solicitadas possibilidades de quem percebe sentir a frieza de maneiras específicas; a vermelhidão do vermelho mostra-se em modos de o vermelho aparecer, solicitando para tanto, possibilidade de quem olha distinguir cores, luz, etc. A inteligência de uma pessoa é passível de ser percebida nas ações contextualizadas em nuanças de modos de proceder por aquele que percebe. Não há uma separação entre o percebido e a percepção de quem percebe, uma vez que é exigida uma correlação de sintonia, entendida como doação, no sentido de exposição, entre ambos. Nesta perspectiva não se assume uma definição prévia do que será observado na percepção, mas fica-se atento ao que se mostra. E, segundo Merleau-Ponty (1990), a percepção dá-nos 'verdades' como presença, o que significa que a clareza do percebido dá-se pontualmente no momento do ato da percepção. Passado o momento, restam os atos da consciência - psicológicos, cognitivos, de ajuizamento - que articulam o percebido, organizando-o e expressando-o em linguagem. Assim, o que se tem é a expressão do percebido expressado pela linguagem - falada, escrita, artística, mítica etc. É nesse aspecto que a descrição é básica para essa perspectiva de pesquisa. Uma vez expressado e comunicado, o percebido já não é do sujeito, mas está apresentado (dado) à comunidade, solicitando, então, procedimentos de análise e interpretação.

Aqui, portanto, abrem-se bifurcações possíveis resultantes de compreensão e de má compreensão do modo de se ver os pares fenômeno/percebido e objeto/observado.

O par fenômeno/percebido caracteriza a concepção fenomenológica de realidade e de conhecimento (BICUDO, 2000) e solicita que a descrição e o que expressa sejam analisadas e interpretadas, atentando-se para a ambiguidade própria da linguagem, dada a densidão de sentidos que ela transporta. Não se tem, a priori, um quadro de categorias de como se deve interpretar o relatado, mas há que se ficar atento ao rigor para não se cair prisioneiro do "achismo", pontificando-se sobre o que ali está dito a partir de visões particulares, quer sejam do próprio investigador, quer sejam de autores estudados. Porém, deve-se adentrar pelos meandros das possibilidades do dito no dizer, buscando-se sentidos transportados tradicionalmente pela palavra, no próprio texto da descrição e do seu contexto, e investigar-se outras características que se mostrarem relevantes ao pesquisador da perspectiva da interrogação formulada. A análise e 
interpretação podem ou não ser conduzidas por articulações de sentidos manifestados, caminhando-se em direção às convergências/divergências e explicitação das compreensões que vão se constituindo. Não se obtém verdades lógicas sobre o investigado, mas indicações de seus modos de ser e de se mostrar. Obtêm-se, portanto, generalidades expressas pelas convergências articuladas.

Esse modo de proceder vem ao encontro de discursos que criticam o cartesianismo e o positivismo, no que têm de determinante, categórico, objetivo e mensurável e é consonante com discursos que promulgam a inseparabilidade entre sujeito e objeto, a impossibilidade de se ter apenas um modo de ver o estudado, bem como com a relevância dos contextos histórico, político e social em que o estudado se situa e com a impossibilidade de aprisionar-se o dito na linguagem em caixas de interpretação.

Entretanto, é comum encontrar pesquisas que assumem, no discurso, a inseparabilidade do sujeito/objeto e demais aspectos apontados no parágrafo anterior, mas que acabam, por má compreensão da profundidade do qualitativo, tomando informações de autores e de teorias a fim de interpretar o dito nas descrições ou mesmo para interpretá-las de modo pragmático e paradigmático. Desta forma, não abrem a linguagem às interpretações possíveis de sentidos relevantes ao contexto investigação/ investigado e àqueles carregados na tradição transportada pela linguagem, mas efetuam interpretações diretas. Tem-se, desse modo, uma confusão entre o solicitado pelos dois pares, em termos de compreensão de visão da realidade do objeto/fenômeno e observação/percepção.

Dadas as características da pesquisa qualitativa, o fenômeno investigado é sempre situado/contextualizado (BICUDO, 2005). Exploram-se as nuanças dos modos de a qualidade mostrar-se e explicitam-se compreensões e interpretações. Sendo assim, os dados trabalhados não se permitem generalizar e transferir para outros contextos. Admitem apenas tecerem-se generalidades sustentadas por articulações efetuadas sucessivamente com os sentidos do que está sendo expresso. São pesquisas que permitem compreender características do fenômeno investigado e que, ao assim procederem, oferecem oportunidade para possibilidades de compreensões possíveis quando a interrogação do fenômeno é dirigida a contextos diferentes daquele em que a investigação foi efetuada. Sustentam raciocínios articuladores importantes para tomadas de decisão políticas, educacionais, de pesquisa e, aos poucos, semeiam regiões de inquérito com análises e interpretações rigorosas.

\section{Aspectos filosóficos a serem considerados}

Pesquisa pressupõe perquirir, de modo atento e rigoroso, o que nos chama a atenção e nos causa desconforto e perplexidade. A priori, não há um modo correto ou certo de pesquisar. Isso significa dizer que não há um padrão de procedimentos a serem seguidos que garantam que 
a investigação seja bem sucedida, dando-nos certeza sobre o encontrado, em termos científicofilosóficos. Também não há primazia, a priori, do qualitativo sobre o quantitativo e respectivos procedimentos de análise e de interpretação. $O$ que temos são interrogações que indicam para onde o olhar se dirige, focando o fenômeno em suas perspectivas e modos de apresentar-se, dando-se a conhecer.

A interrogação é correlata ao interrogado e a quem interroga. Essa complexidade não pode ser ignorada ou menosprezada.

Ao falar que o interrogado - fenômeno - se doa em modos de aparecer, não estamos dizendo que há algo em si que decida se mostrar deste ou daquele modo. Chamamos a atenção para os modos de isso que interrogamos estar no mundo contextualizado em fisicalidades ${ }^{3}$ específicas que têm a ver com matéria-forma e que não se aprisiona ao como se mostra em certo momento, pois também está em movimento, como em movimento estão quem pergunta e a própria pergunta.

Sendo assim, a complexidade interrogação-interrogado-quem interroga há que ser ouvida, buscando compreender do que se trata a investigação em movimento. Por exemplo, perguntas como: que aspectos são importantes destacar em termos da interrogação formulada? Neste contexto, frente às condições atuais, devo dar relevância a quais aspectos do visto? Isso que interrogo, pode se mostrar de maneira apropriada quantitativa, qualitativa, qualiquantitativamente?

As considerações apresentadas indicam que a interrogação/pergunta/problema assume destaque na investigação filosófico-científica.

\section{A interrogação}

Em nossos trabalhos temos, reiteradamente, afirmado que pesquisar é perseguir uma interrogação em diferentes perspectivas, de maneira que a ela podemos voltar uma vez e outra ainda e mais outra. A interrogação se comporta como se fosse um pano de fundo onde as perguntas do pesquisador encontram seu solo, fazendo sentido. Ela persiste, ainda que a pergunta específica de um determinado projeto seja abordada, dando-se conta do indagado. A interrogação interroga. O que ela interroga? O mundo. Não o mundo em sua generalidade vazia, mas aspectos específicos do mundo que se mostram em suas fisicalidades pragmáticas, teóricas, tecnológicas, ideológicas. Ela se constitui no norte que dá direção aos procedimentos da pesquisa.

3 Por fisicalidades entendemos modos de realidades físicas estarem ao mundo, doando-se em materialidades que podem ser observadas, contadas, etc. 
Entendemos que o ponto crucial da pesquisa é constituído pela interrogação e seu esclarecimento. Daí fazer sentido perguntarmo-nos constantemente o que a interrogação interroga? ${ }^{4}$. O movimento efetuado para dar conta dessa busca auxilia a focar no o quê, contribuindo para que pensemos reflexivamente no como proceder para corresponder ao indagado.

A interrogação é diferente da pergunta, que indaga, solicitando esclarecimentos e explicitações; do problema, que explicita a pergunta, problematizando uma situação de maneira mais discursiva ou colocando as variáveis já determinadas que o constitua sob a forma de uma equação algébrica; da hipótese colocada sob suspeita, cuja confirmação ou negação fica por conta da pesquisa efetuada. Compreendemos que a interrogação subjaz a essas modalidades e que formular problemas, hipóteses e perguntas são maneiras de assumir perspectivas a partir das quais a interrogação será perseguida. Ela diz da perplexidade do investigador diante do mundo, a qual se manifesta inclusive como força que o mantém alerta buscando, perquirindo, não se conformando com respostas quaisquer. As formas pelas quais a interrogação é explicitada são múltiplas e têm a ver com a própria formação do pesquisador e com sua concepção de mundo e de ciência. A interrogação persiste, muitas vezes, ao longo da vida do pesquisador ${ }^{5}$ ou mantém-se durante muito tempo com a força que, como a physis ${ }^{6}$, faz brotar e manter-se sendo.

Como afirmamos acima, entendemos que mesmo para pesquisadores que trabalham com teorias tradicionalmente formuladas e constituídas, ou nem tanto, no âmago da qual formulam suas perguntas e hipóteses, há sempre uma interrogação que dirige seus olhares e opções, sustentando-os no movimento da investigação. Notamos que em muitos trabalhos, certamente não daqueles de pesquisadores de ponta, há ausência de compreensão do significado da pergunta formulada, bem como das características da realidade - sempre dadas em perspectiva - em que se movimentam. Acreditamos que atenção a esses aspectos por parte dos próprios investigadores e formadores de pesquisadores é crucial para desdobramentos de posturas assumidas em termos de crença na certeza absoluta, evitando que se caia prisioneiro de posturas céticas niilistas, e,

\footnotetext{
${ }^{4}$ Para o leitor que quiser aprofundar a questão concernente à interrogação, sugerimos a leitura de Martin Heidegger (1998) como a inspiradora destas reflexões, e a de Kluth (2001), texto que já elabora os sentidos que se mostram em Heidegger, olhados na perspectiva daqueles que, iniciando-se na produção de pesquisas, estão em busca de maior rigor em suas investigações.

${ }^{5}$ Como exemplo, citamos o caso de Edmund Husserl que, durante toda sua vida de estudioso manteve-se perplexo diante da interrogação que formulou sobre a origem da aritmética, depois, também explicitada como origem da geometria (Husserl, E. 1970).

${ }^{6}$ Ver Heidegger, M. Heráclito, 1998.
} 
também, assumidas em termos de posições éticas e ideológicas, sustentadas naquelas pesquisas, entendendo-as como cientificamente corretas.

\section{Possibilidades de pesquisar-se qualitativamente em abordagem fenomenológico/hermenêutica}

Como já afirmado anteriormente, estamos focando a pesquisa qualitativa que assume procedimentos no horizonte da visão de realidade e de conhecimento que vem sendo trabalhada e dada ao mundo por pensadores que têm sido denominados fenomenólogos. Dentre esses destacamos seu mentor maior e iniciante, Edmund Husserl, e estudiosos que, embora dissidentes do pensar de seu mestre, não se distanciaram de ideias nucleares desse modo de ver o mundo, como Heidegger, Gadamer, Merleau-Ponty, para ficarmos entre os que viveram em uma época mais próxima àquela em que Husserl viveu ${ }^{7}$. Com essa afirmação, estamos dizendo que na atualidade, ou seja, das décadas de 1980 para o momento atual, 2012, há autores cujas trajetórias filosóficas se movimentam no solo das ideias fenomenológicas, avançando em termos de trabalhar com a complexidade mediante a qual nossa realidade mundana se mostra. Para exemplificar, dentre os brasileiros citamos Paulo Freire e os oriundos de outros países, Ricoeur e Foucault.

Dado o contexto desta exposição, apresentaremos modalidades de modos de proceder fenomenológica e hermeneuticamente ao interrogarmos temas específicos da Educação Matemática, uma vez que esse tem sido nosso campo de investigação ao longo dos últimos quase trinta anos. Nessa trajetória sempre trabalhamos com nossos orientandos e na medida em que fomos constituindo nosso caminhar e nele nossas compreensões, dúvidas, certezas, mantivemonos juntos no movimento do próprio processo de ir adiante, produzindo conhecimento e criticando o produzido e os modos pelos quais isso foi produzido, isto é, a metodologia assumida. Desse modo, constituímos um núcleo de pesquisa, em nossos meios chamado de grupo de pesquisa, denominado Fenomenologia em Educação Matemática - FEM.

Nessa temporalidade vivida realizamos pesquisas cujas interrogações perguntam pelo 0 quê do fenômeno focado, solicitando procedimentos que entendemos, à luz da literatura estudada, como evidenciando o estruturante do fenômeno. Neste caso, trabalhamos com reduções sucessivas, porém, entendemos, na historicidade da produção do grupo, que é preciso considerar o enxerto hermenêutico, já mencionado por Heidegger (1988) e trabalhado também por Ricoeur $(1986 ; 1988)$, no intuito de abrirmos possibilidades de compreensões dos sentidos conduzidos pela linguagem mediante a qual os sujeitos, da pesquisa, expressavam suas vivências.

\footnotetext{
${ }^{7}$ Edmund Husserl nasceu em 1859 e morreu em 1938.
} 
Há pesquisas que focam o como, solicitando atenção ao tempo vivido nas vivências dos sujeitos investigados. Neste caso, também se obtêm relatos/descrições das experiências vividas, tanto por meio de depoimentos falados, gravados e transcritos, como por meio de filmagens em vídeo, dentre outras possibilidades. Esses modos de obter as descrições trazem questões importantes para os procedimentos.

No primeiro caso, o pesquisador se debruça sobre o texto escrito oriundo da fala (gravada, escrita) e procede mediante leituras atentas, com a intenção de destacar o que de importante, em ralação à interrogação, está sendo dito. Desdobra a pesquisa em análises de sentidos/significados que se doam à compreensão mediante idas e vindas ao que o depoente diz, ao seu contexto de vida, à polissemia das palavras, de maneira que no movimento das reduções efetuadas, ocorre a abertura para a complexidade dos significados, preparando a análise hermenêutica.

O segundo caso, concernente à filmagem de situações, mais especificamente em Detoni e Paulo (2011), a descrição apresenta aspectos qualitativos diferenciados uma vez que a linguagem, mediante a qual a descrição se dá à análise, se expressa pela oralidade e pela intencionalidade do corpo-próprio, expondo-se em gestos, ações, movimentos cujo sentido se compreende no contexto da cena, em que estão figura e fundo, portanto o sujeito, co-sujeitos e tema trabalhado que sustenta a cena. Para nós foi desafiador trabalhar com dados obtidos desse modo, de maneira a preservar a riqueza dos diálogos entre sujeitos que, por exemplo, em ambiente de aprendizagem onde estão presentes alunos e professores, dão-se concomitantemente e em diferentes linguagens.

A maneira pela qual enfrentamos esse desafio e respectivas concepções assumidas no desenrolar das investigações conduziu-nos à construção de redes de significados que se enredam uns nos outros, como se fossem camadas de sentidos não apenas superpostos, mas cujos tentáculos interpenetram uns sentidos em outros, evidenciando a nucleação de significações. Essa modalidade de interpretação e de apresentação dos dados é solicitada quando, ao proceder-se às reduções, os significados não se aglutinam em invariantes que podem ser nomeados de maneira mais abrangentes, ou seja, por meio de categorias abertas, mas que se mostram em um emaranhado complexo, conforme exposto no trabalho de Kluth (2011).

Ainda trabalhamos qualitativamente, consonantes com as concepções fenomenológicas e hermenêuticas, textos historicamente situados, sejam eles documentos institucionais, textos filosófico-científicos que se mostram apropriados à interrogação formulada. Essa modalidade de pesquisa solicita que o pesquisador direcione sua atenção para o discurso do texto, lido e interpretado à luz da interrogação posta. Em Bicudo, Mocrosky e Baumann (2011), as nuanças de modos qualitativos de proceder se mostram, indicando percursos. Uma interrogação dirigida, por exemplo, ao Projeto Pedagógico de um curso, perguntando sobre o que é esse projeto, em termos de concepções de arte, ciência e tecnologia, de educação, de ideologia, etc., pede que 
tomemos o documento que traz esse projeto, analisando-o apoiados em procedimentos hermenêuticos e lendo-o por entre as articulações efetuadas no próprio movimento de investigar. Interrogações que interrogam núcleos genéticos de constituição de ideias e conceitos científicos, por exemplo, solicitam um olhar atento à historicidade dessa constituição, o que já envolve concepção de história e possibilidades de trabalhar-se nessa dimensão da realidade humana, assumindo-se postura fenomenológica. Esses modos de analisar e interpretar projetos pedagógicos permite que avancemos em compreensões para além das informações trazidas pelas leituras primeiras da proposta. Por fim, mas não por último, em Kluth (2007), abordamos a concepção de história como assumida por Edmund Husserl e tecemos considerações de possibilidades de procedimentos consonantes com essa concepção.

\section{Dando conta do compreendido do tema}

A pesquisa em Educação Matemática mostra-se, na historicidade dessa área de inquérito, como efetuada, na grande maioria das vezes, de modo qualitativo. Essa é uma de suas características que faz sentido ao indagarmos pelo que se busca saber ao procedermos as investigações. Podemos apontar em um grande leque de possibilidades de temas de pesquisa, por exemplo, aquelas que buscam por compreensões de modos pelos quais os alunos constroem suas aprendizagens (de matemática), individualmente, com os colegas, com a mídia, em contextos específicos; de atividades de ensino, da realidade escolar, dos textos que servem de mediadores ao ensino, mas que não são entendidos como neutros ideológica e cientificamente, donde atentar-se pelo que dizem além do dito. 0 mesmo ocorre com os documentos que sustentam instituições e a própria Educação Pública.

Entretanto, fiquemos atentos: é uma investigação efetuada na academia e, portanto, já delineada em um contexto de exigências que apontam para o rigor mantido em relação aos procedimentos. Donde, o efetuado solicitar por clareza dos caminhos percorridos e a percorrer, os quais devem, sempre, evidenciar consonância entre as características disso que se busca e os modos pelos quais se procede ao efetuar a busca.

Para mim, também se mostra como relevante o fato de esta 'área' ser denominada 'Educação Matemática' a qual, como já sabemos, é constituída no 'entre' a Educação e a Matemática, de modo que essa esfera do entre, tomando aqui os dizeres de Martim Buber (1977), constitui uma realidade específica. Realidade essa em que Educação e Matemática dialogam, ou seja, oferecem-se ao trabalho da produção de conhecimento buscado. Portanto, não podem ser caladas, nem ser tomadas isoladamente ou uma sobrepor-se à outra.

Isso significa, conforme minha compreensão, que ao pesquisador em Educação Matemáticas ambas as esferas de saber devem estar presentes, constituindo o solo em que seu 
pensar $^{8}$ se movimenta, donde a lógica de produção de ambas as disciplinas, bem como os respectivos conteúdos temáticos e discursos que articulam as ideias que se mostram nucleares aos seus campos de significados devem ser de domínio do seu cotidiano.

\section{Referências}

BICUDO, M.A.V. Fenomenologia: Confrontos e Avanços. São Paulo: Cortez editora, 2000.

BICUDO , M.A.V. Pesquisa Qualitativa e Pesquisa Qualitativa segundo a abordagem fenomenológica IN : Borba, M.C; Araujo, J.L. (orgs). Pesquisa Qualitativa em Educação Matemática. Belo Horizonte: Autêntica, 2004, p.99-112.

BICUDO, M.A.V. Pesquisa Qualitativa; Significados e a Razão que a Sustenta. Revista Pesquisa Qualitativa, São Paulo, Ano 1, n.1, 2005, p. 7-26.

BICUDO, M.A.V (org). A pesquisa Qualitativa segundo a visão fenomenológica. São Paulo: Cortez Editora, 2011.

BICUDO, M.A.V.; PAULO, R.M. Um exercício filosófico sobre a pesquisa em educação matemática. Bolema, Rio Claro, vol 25, n. 41, dezembro de 2011, p. 251-298.

BUBER, M. Eu e Tu. São Paulo: Cortez \& Moraes, 1977.

DETONI, A.R.; PAULO, R.M. A organização dos dados da pesquisa em cena: um movimento possível de análise. IN: BICUDO.(org). A pesquisa Qualitativa segundo a visão fenomenológica. São Paulo: Cortez Editora, 2011.

HEIDEGGER, Martin. Ser e Tempo. Petrópolis: Vozes, 1988.

HEIDEGGER, Martin. Heráclito. Rio de Janeiro: Relume Dumará, 1998.

HUSSERL, E. Crisis of European Science. Evanston: Northewestern University Press, 1970.

KLUTH, V.S. Dos Significados da Interrogação para a Investigação em Educação Matemática. Bolema, Rio Claro, n.15, 2001, p. 69-82.

KLUTH, V.S. Estruturas da Álgebra: Investigação fenomenológica sobre seu conhecimento. Tese de doutorado. Instituto de Geociências e Ciências Exatas, Universidade Estadual Paulista, Rio Claro, 2007.

\footnotetext{
${ }^{8}$ Por pensar, conforme aqui está sendo tomado, entendam-se ações, modos de tomar decisões, proceder as intervenções, ou seja, não se refere a um significado que indique um processo cognitivo subjetivo, apenas.
} 
KLUTH, V.S. A organização dos dados da pesquisa em cena: um movimento possível de análise. IN: BICUDO (org). A pesquisa Qualitativa segundo a visão fenomenológica. São Paulo: Cortez Editora, 2011.

MERLEAU-PONTY, Maurice. O primado da percepção e suas conseqüências filosóficas. Campinas: Papirus, 1990.

BICUDO, M. A. V.; MOCROSKY, L. f.; BAUMANN, A.P.P. Análise qualitativo-fenomenológica de projeto pedagógico. IN: BICUDO, (org). A pesquisa Qualitativa segundo a visão fenomenológica. São Paulo: Cortez Editora, 2011.

RICOEUR, P. Du text à l'action. Essais d’herméneutique, II. Paris: Éditions Du Seul, 1986.

RICOEUR, P. Interpretação e Ideologias. (3a edição). Rio de Janeiro: Francisco Alves, 1988.

Maria Aparecida Viggiani Bicudo. Professora do Programa de Pós-Graduação em Educação Matemática da UNESP, Rio Claro. Coordenadora do Grupo de Pesquisa de Fenomenologia em Educação Matemática. Pesquisadora CNPq. mariabicudo@gmail.com 